\title{
Artelogie
}

arte ogie

Recherche sur les arts, le patrimoine et la littérature de l'Amérique latine

$4 \mid 2013$

Fêtes et célébrations en Amérique latine

\section{El fin de fiesta del Uruguay : la decadencia individual como metáfora del declive colectivo en el relato "Bienvenido Bob", de Juan Carlos Onetti}

\section{Giuseppe Gatti}

\section{(2) OpenEdition}

\section{Journals}

Edición electrónica

URL: https://journals.openedition.org/artelogie/6073

DOI: 10.4000/artelogie.6073

ISSN: 2115-6395

Editor

Association ESCAL

Referencia electrónica

Giuseppe Gatti, «El fin de fiesta del Uruguay : la decadencia individual como metáfora del declive colectivo en el relato "Bienvenido Bob", de Juan Carlos Onetti», Artelogie [En línea], 4 | 2013, Publicado el 02 febrero 2013, consultado el 01 diciembre 2021. URL: http://journals.openedition.org/artelogie/ 6073 ; DOI: https://doi.org/10.4000/artelogie.6073

Este documento fue generado automáticamente el 1 diciembre 2021.

Association ESCAL 


\section{El fin de fiesta del Uruguay : la decadencia individual como metáfora del declive colectivo en el relato "Bienvenido Bob", de Juan Carlos Onetti}

\section{Giuseppe Gatti}

Je me sentais vivre en elle, et elle vivait pour moi seul. Son sourire me remplissait d'une béatitude infinie; la vibration de sa voix si douce et cependant fortement timbrée me faisait tressaillir de joie et d'amour. Elle avait pour moi toutes les perfections, elle répondait à tous mes enthousiasmes, à tous mes caprices. (Nerval) Le printemps et venu, puis il a passé. L’été est venu, et il passe, tout lentement, gros et lourd

avec ses gros pieds embourbés de soleil qui pèsent sur nos têtes. (Jean Giono)

1 En el contexto geosocial y cultural del continente latinoamericano la conciencia colectiva había elaborado y se había adueñado de un proceso asociativo que vinculaba el término "Suiza de América" a la República Oriental del Uruguay y aducía la definición de "Atenas del Plata" a su capital, Montevideo'. El empleo -y el abuso-de estas definiciones suelen referirse, desde un punto de vista cronológico, al período histórico comprendido entre 1903 y 1950, fechas no meramente convencionales en tanto coinciden respectivamente con el primer mandato presidencial de José Batlle y Ordoñez ${ }^{2}$, después de su larga estancia en Europa, y el triunfo futbolístico de la selección charrúa en la Copa del Mundo de 1950, en Brasil. Si bien en el imaginario nacional y continental se tiende a hacer coincidir la fecha del éxito mundialista con el comienzo del declive socioeconómico y cultural del país, existen motivos no sólo para 
sustentar la tesis que adelanta a la década del treinta el incipit del quiebre sistémico nacional, sino también para afirmar que un grupo de intelectuales pertenecientes a la Generación del ' 45 (entre otros, Fernando Aínsa, Carlos Maggi, Carlos Martínez Moreno, José Pedro Díaz) había ubicado los primeros síntomas del declive a mediados de los años treinta. Nuestro análisis del relato "Bienvenido Bob", narración emblemática de la inexorabilidad del desgaste producido en el ser humano por el transcurso del tiempo, se propone mostrar cómo una serie de elementos alegóricos presentes en el texto onettiano confirmarían la tesis de la lúcida percepción por parte de su autor del camino tomado por el Uruguay. La cronología de su redacción, como se verá más adelante, sostiene esta línea; el relato se publicó en Buenos Aires en 1944 y más tarde se incluyó en la recopilación Tan triste como ella y otros relatos que Juan Carlos Onetti dio a la imprenta en Montevideo, en 1963.

2 La relectura del cuento que se propone en nuestro estudio intenta añadir al consolidado examen del motivo "clásico" de la venganza otro foco de atención: se concentrará el interés en la subjetividad de la percepción del paso del tiempo -subrayando la distinción entre tiempo vivido (o individual) y tiempo físico (o colectivo)-y en la decadencia física y moral del ser humano, interpretada como expresión alegórica del incipiente declive de un país entero. No es irrelevante notar cómo la ambientación realista de la narración en examen se opone a las dinámicas de evasión de la realidad por medio de la fantasía y la ensoñación que caracterizan la obra onettiana y que supusieron la creación de Santa María, primera ciudad imaginaria de la literatura hispanoamericana. El contraste parece evidente, en particular, en la gestión de las coordenadas temporales de la ficción: mientras la saga de la ciudad a orillas del río Paraná es contada sin que respete un rígido orden cronológico (recordemos que si es en El Astillero, publicado en 1961, donde se cuenta ambiguamente la "posible muerte" de Larsen, sin embargo, es sobre todo en Juntacadáveres, de 1964, donde se construyen tanto la biografía como el primer fracaso del personaje central de la trama ${ }^{3}$ ), la cronología rigurosa según la que se desarrolla "Bienvenido Bob" resulta clave -como se verá- tanto para la articulación de la atmósfera de deterioro progresivo de sus alicaídos protagonistas como para la representación de las diferencias perceptivas en la duración íntima del tiempo para cada uno de ellos.

3 Ambas condiciones confluyen hacia una posible lectura simbólica que remite al todavía embrional derrumbe del sistema social batllista y de los modelos económicos adoptados por el país, que habían permanecido válidos hasta el comienzo de la Segunda Guerra Mundial. La existencia de una relación alegórica entre la demolición interior del personaje ficcional que da el nombre al relato y la consagración de la decadencia de un orden caduco y desgastado es subrayada por Fernando Aínsa quien sugiere cómo, en la construcción de sus personajes, Onetti "trabaja ese desgaste insidioso de la vitalidad y el entusiasmo, esa degradación continua -aunque durante años parezca invisible- y por lo tanto irremediable cuando se toma conciencia de ella" (Aínsa, 2008: 57).

4 Así, a pesar de que el carnaval uruguayo siga siendo el más largo del mundo y convoque durante cuarenta días a decenas de miles de personas, pese a que el sonido de los tambores del Candombe durante los desfiles carnavalescos siga llenando las noches de los barrios Sur y Palermo y que los grupos de murga ${ }^{4}$ creen una creciente expectativa en el público que se acerca a los tablados citadinos, la persistencia de estos fenómenos socioculturales no puede ocultar que el país lleve más de 70 años flotando en una condición-limbo que transfiere una sensación difusa de fin de fiesta. La alegría 
despreocupada de las décadas anteriores a la Segunda Guerra Mundial se ha eclipsado dejando lugar a una percepción dilatada de desilusión nostálgica, fortalecida por la sensación de resquebrajamiento de las instituciones responsable de la pasada prosperidad y la involución de las normas y reformas constitucionales.

\section{Temporalidad subjetiva y declive objetivo en la superposición de los tiempos narrativos}

5 La primera operación necesaria para el abordaje del texto parece ser la identificación de dos motivos, en particular, que conectan "Bienvenido Bob" con la gran producción novelística onettiana. Destacan sobre todo:

1. El motivo del regreso. En el caso de la saga de Santa María, el retorno de Larsen se justifica a partir de su deseo de poner en marcha una revancha social hacia los habitantes de la ciudad. En el caso del narrador de "Bienvenido Bob", el concepto de regreso se expresa de una forma peculiar: después de una elipsis temporal de diez años, el narrador en primera persona informa al lector de que ambos personajes masculinos (la voz que narra y el joven Bob) han vuelto a encontrarse en el mismo club donde la historia tuvo su comienzo, sin que se relate lo ocurrido en el tiempo incluido entre las dos fechas. Lo que interesa en la construcción ficcional es el regreso al mismo espacio físico (el "boliche") en un tiempo distinto, como si Onetti se propusiera un doble objetivo: por una parte, describir una irrupción postergada en el relato de aquellos hechos que el narrador -desde el comienzo del cuento- está seguro de que ocurrirán y, por otra parte, ficcionalizar el retorno a un espacio común de dos seres (los protagonistas masculinos del relato) que han asumido su derrota y comparten -aun si individualmente- la sensación del fin de fiesta.

2. El motivo del pasado que vuelve a proponerse. Este proceso ocurre a partir de fragmentos que el lector tiene que reconstruir y poner en orden (no es casualidad, en este sentido, el hecho de que el pasado de Larsen resulte desconocido para el lector: en El Astillero su biografía no se ha contado todavía, dado el desajuste temporal que aventaja su publicación a la de Juntacadáveres); en "Bienvenido Bob" el intervalo temporal comprendido entre la ruptura forzada de la relación sentimental del narrador con el personaje femenino y su reaparición en el mismo café no se narra, porque lo que importa -en un primer nivel de lectura- parece no ser el tiempo exterior, colectivo, de esos diez años, sino los dos tiempos individuales del narrador y de su "rival": un doble tiempo marcado por la paciente espera del uno y por el paulatino e inexorable desgaste del otro.

6 Los diez años transcurridos entre los primeros encuentros de los protagonistas y el desenlace del cuento adquieren una centralidad determinante en tanto que reflejan una temporalidad propia del protagonista-narrador, para quien la historicidad -entendida como expresión de un tiempo que pretendería ser colectivo-parece importar únicamente como mero "instrumento" individual para su lenta venganza ${ }^{5}$. Es así que en una narración construida alrededor del inexorable transcurso del tiempo, un relator interno es quien se encarga de contar la historia: se trata de uno de los dos protagonistas masculinos (el tercer personaje es la joven hermana de Bob, Inés, quien proyecta su sombra silenciosa sobre la trama). La focalización interna permite relatar los hechos a partir de una perspectiva parcial, que ofrece una visión individual y sesgada de las afecciones desatadas por los desencuentros del narrador con Bob y por el recuerdo de las reiteradas y despectivas actitudes de este último.

7 Sin embargo, paralelamente a esta visión subjetiva de las coordenadas temporales, la centralidad en la trama onettiana de los diez años transcurridos entre los primeros 
encuentros juveniles de los tres protagonistas y los momentos conclusivos del relato se confirma -en un plano alegórico- si se analiza detenidamente la cronología del proceso de decadencia que tuvo que enfrentar el país y la paulatina descomposición de los cimientos en los que se fundaba el sistema batllista. Un abordaje de naturaleza sociohistórica y política demostraría que el comienzo de la pauperización implantó sus raíces en el Uruguay ya a partir de la década del treinta, según una interpretación analítica compartida por la mayoría de los intelectuales de la Generación del '45. El inicio del fin se inauguraría a partir del golpe de Estado del 31 de marzo de 1933, de tal manera que si se quisera encontrar una periodización que dé cuenta de los cambios en la sensibilidad nacional, se podría sostener que la acción militar llevada a cabo por Gabriel Terra marcó el comienzo del naufragio de un mundo y una época. No es casual, y consolida la lectura metafórica que se está proponiendo, que Onetti redactara el cuento justo en el año 1943 (publicándolo el año siguiente en la Argentina), precisamente diez años después de ese hito nefasto de la historia nacional.

La composición de la arquitectura temporal es clave, como se ha adelantado, para el desarrollo del plot narrativo: desde el incipit, se pone de relieve la importancia del uso de los tiempos verbales. Así relata el protagonista: "Es seguro que cada día estará más viejo, más lejos del tiempo en que se llamaba Bob, del pelo rubio colgando en la sien, la sonrisa y los lustrosos ojos de cuando entraba silencioso en la sala [...] e iba a sentarse bajo la lámpara, cerca del piano, [...] mirándonos durante una hora sin un gesto de la cara" (Onetti, 1975: 62). El primer plano es el del tiempo de la narración, expresado por las certezas contenidas en el uso del tiempo presente: "es". El segundo plano expresa la proyección de la historia hacia un futuro que no se contará y que -sin embargo- es presentado por el narrador como una certeza irrefutable; aparece reflejado por el uso del tiempo futuro: "estará". Finalmente, el tercer plano narrativo es el tiempo de lo ocurrido en la primera sección del cuento, en el que se ubican los primeros dos tercios de la narración: esta dimensión temporal se expresa mediante por el uso del imperfecto: "se llamaba", que remite a un tiempo feliz y perdido perteneciente al espacio de detrás.

9 Esta temporalidad del espacio permite reflexionar acerca de cómo, en todo ser humano, la coexistencia de formas de vida del pasado y del presente crea la necesidad de establecer un equilibrio entre recuerdo y esperanza, así como sugiere Alfonso Reyes: "Los hombres sienten la necesidad [...] de figurarse que proceden de otra era mejor y caminan hacia otra era mejor; que se han dejado a la espalda un paraíso ya perdido y tienen por delante nada menos que la conquista de un cielo, aunque sea un cielo terrestre" (Reyes, 1993: 341). El tiempo no sólo se espacializa como recuerdo (rememoración nostálgica de una juventud en la que todo parecía todavía posible, y rememoración metafórica de un orden armónico y de una concepción del mundo que se han ido vaciando y disgregando), sino que se proyecta hacia la esperanza-ilusoria y patética si examinada a posteriori-de poder acceder, de nuevo, al presunto Edén perdido. En términos cronológicos y de percepción del tiempo, la noción del Uruguay como sistema detenido se refleja en una cultura que ensalza ex post y hasta su glorificación aquel espacio-tiempo mítico constituido por grandes acontecimientos de la historia nacional, elaborando una visión de un presente fracasado centrada en una nostálgica comparación.

En el relato, el proceso de inmisión en los cambios todavía no explicitados que acontecen durante el tiempo de la narración ocurre de manera directa e inmediata: el 
narrador revela la existencia de una insalvable distancia temporal entre el recuerdo que él guarda del Bob joven, cuya arrogancia se ha hundido ahora en la triste memoria de un pasado sofocado por el peso de los años, y las miserias de un presente de desilusión existencial ${ }^{6} \mathrm{y}$ fracaso debido a una "acumulación del tiempo" que desgasta. Así lo relata Onetti: "Igualmente lejos -ahora que se llama Roberto y se emborracha con cualquier cosa, protegiéndose la boca con la mano sucia cuando tose- del Bob que tomaba cerveza, dos vasos solamente en las más largas de las noches, con una pila de monedas de diez sobre su mesa de la cantina del club" (Onetti, 1975: 62). El uso de dos nombres para referirse a la misma persona, es decir, el cambio del nombre de Bob a Roberto, es el elemento que indica que alguna modificación sustancial e irreversible ha ocurrido durante la narración, un cambio subjetivo debido a los diez años que han transcurrido entre la primera parte y la segunda. La misma condición de irreversibilidad de los cambios producidos por el paso del tiempo se percibe en el lento desmoronamiento del orden socioeconómico en el que se había sustentado la imagen de Uruguay como excepción dentro del panorama continental. La república modélica de las primeras décadas del siglo XX entraba a comienzos de los '40 en su última etapa áurea, creyéndose todavía una afortunada excepción dentro del contexto geográfico latinoamericano: el país vivía en la inconsciencia de seguir siendo la "Suiza de América", sin que ya existieran los presupuestos económicos, políticos y socioculturales para sustentar ese presunto rol modélico.

11 Afirmar que el relato onettiano se construye alrededor de una doble percepción individual del tiempo obliga a aclarar que se trata de un tiempo psicológico, personal, que Onetti -a la manera bergsoniana- enlaza con el tiempo exterior y colectivo. Según afirma el joven Bob, tener treinta o cuarenta años significa la vejez, el derrumbe de las ilusiones, en base a una lógica interpretativa de la temporalidad que nace de una percepción subjetiva y alterada del paso del tiempo y que -al mismo tiempo-remite a la alarma simbólica que el autor lanza acerca de la imposibilidad de alcanzar el "país de la juventud". La primera sección del cuento, dedicada al pasado juvenil de Bob, muestra al lector un estudiante de arquitectura arrogante y presumido, ilusionado con grandes proyectos personales (construir una inmensa ciudad a orillas del mar): "También con algún otro muchacho, los sábados, alguno tan rabiosamente joven como él, con quien conversaba de solos, trompas y coros y de la infinita ciudad que Bob construiría sobre la costa cuando fuera arquitecto" (Onetti, 1975: 62). La entrada en escena del tercer personaje, Inés-de la que el narrador resulta aparentemente enamorado y correspondido-, ocurre de una forma indirecta y peculiar: el relator la describe basándose en definiciones comparativas, como si lo verdaderamente relevante fueran las similitudes estéticas de la muchacha con su hermano: "En aquel tiempo Bob era muy parecido a Inés; podía ver algo de ella en su cara a través del salón del club, y acaso alguna noche lo haya mirado como la miraba a ella" (Onetti, 1975: 62). La imagen femenina que aparece en el relato consolida los rasgos estereotipados sobre el rol de la figura de la mujer presentes en las grandes novelas onettianas: en un primer nivel de lectura se aprecia cómo el personaje de Inés está marcado por una marginalidad deliberada en relación con la historia, según el esquema indicado por Fernando Aínsa por el que "el amor [es] predeterminado por la voluntad masculina, dirigido a él, inexorablemente marcado por las inteligencias centrales de sus novelas, siempre masculinas" (Aínsa, 1970: 120). En segundo lugar, como se verá en las páginas que siguen, Inés representa únicamente un "instrumento de salvación potencial e hipotética" para el protagonista masculino, sin que importen su humanidad o sus 
características como individuo, según una tendencia ya expresada en El Pozo (1939), así como lo recuerda Javier de Navascués: "Sin duda la imagen que desea Linacero no se corresponde con ninguna mujer real. [...] Su mujer real debiera ajustarse con exactitud al patrón que él configura en su imaginación" (Navascués, 2007: 138).

La aparición de Inés en la trama es el elemento que desata la confrontación del narrador con el hermano de la muchacha: la razón de existir del continuo enfrentamiento que opone en la narración a los dos personajes masculinos reside en el desprecio de Bob por el maduro pretendiente, percibido como un hombre ya decrépito y gastado. El duelo llega a su cumbre cuando el relator del cuento manifiesta su intención de casarse con Inés: el matrimonio representa su gran proyecto para el futuro, su última gran apuesta para evitar el hundimiento en un mañana de soledad. El narrador, que hasta ese momento de su vida se había negado toda posibilidad de establecer vínculos humanos sólidos, percibe que el proyecto de casarse puede representar una tentativa de salvación, incluso concibe la posibilidad de que la futura vida conyugal con la joven Inés pueda otorgarle la oportunidad de desestabilizar la pasividad arraigada en su condición de "hombre adulto de treinta o cuarenta años". La realidad, sin embargo, resulta ser diferente y revela cómo su presunto amor hacia Inés no es otra cosa que una máscara ilusoria y no del todo consciente: el amor se dirige más bien hacia el proyecto en sí, dejando a la joven hermana de Bob en el rol de mero instrumento para su consecución. El matrimonio sería sólo la herramienta para una reconstrucción personal basada en un sentimiento transitorio destinado a la ilusoria búsqueda de un nuevo principio (obsérvese la nueva referencia alegórica al camino regresivo e irreversible emprendido por el país). Una modalidad de salvación inconsistente que remite al universo de las "pequeñas muertes cotidianas" de las grandes novelas onettianas, un mundo donde-observa Hugo Verani, en su ensayo Onetti: el ritual de la impostura- "la transitoriedad del amor y de todo lo viviente frustra toda tentativa de comunicación, toda esperanza de permanencia" (Verani, 2009: 75). La ilusoria réchérche de otro comienzo posible y la percpeción de la imposibilidad de lograr el objetio se extienden, en la alegoría onettiana, del espacio sujetivo al sistema-país, en el que faltan los presupuestos concretos (tanto en términos de recursos nacionales como de dinámicas económico-comerciales globales) para evitar el hundimiento.

El joven, arrogante y agresivo Bob se enfrenta al narrador en manera directa: "Usted no se va a casar con ella porque usted es viejo y ella es joven. No sé si usted tiene treinta o cuarenta años, no importa. Pero usted es un hombre hecho, es decir deshecho, como todos los hombres a su edad cuando no son extraordinarios" (Onetti, 1975: 65). Palabras crueles que destruyen el sueño del narrador; Bob lo agrede definiéndolo un hombre sin futuro, un fracasado: le transmite su desprecio, su percepción de la falta de esperanzas que vislumbra sin excepciones en el mundo de los adultos. La pérdidia del entusiasmo que sólo puede residir en los años juveniles-es vista por Bob como un lastre mensurable e inevitable, que obliga a los hombres ya maduros a razonar y sentir por categorías, negando así la individualidad de los demás individuos: "Estuvo diciendo que en aquello que él llamaba vejez, lo más repugnante, lo que determinaba la descomposición era pensar por conceptos, englobar a las mujeres en la palabra mujer, empujarlas sin cuidado para que pudieran amoldarse al concepto hecho por una pobre experiencia" (Onetti, 1975: 65).

Inés, presencia ausente en la narración, sigue los consejos del hermano: rechaza la propuesta de matrimonio y así derrumba los sueños de su falso pretendiente ${ }^{7}$. Una vez 
más, las elecciones y acciones de la joven son referidas indirectamente, por medio de la reelaboración que de ellas hace el relator: "No vi más a Inés ni tampoco a su forma vacía y endurecida; supe que se casó y que no vive ya en Buenos Aires. Por entonces, en medio del odio y el sufrimiento me gustaba imaginar a Bob imaginando mis hechos y eligiendo la cosa justa o el conjunto de cosas que fue capaz de matarme en Inés y matarla a ella para mí" (Onetti, 1975: 66)

El fracaso de los proyectos matrimoniales, debido a la dura oposición de Bob, dramatiza dos de los motivos centrales de la narrativa onettiana: primero, pone de relieve el divorcio inevitable entre el hombre, sus aspiraciones y deseos, por un lado, y el mundo que lo rodea, por el otro, expresión de un universo indiferente a sus llamados y capaz de crear una distancia espiritual inconmensurable entre sujetos y realidad. Una distancia que se manifiesta en toda su magnitud en las palabras del mismo protagonista: "No sé cómo supo de mi necesidad de casarme con su hermana y de cómo yo había abrazado aquella necesidad con todas las fuerzas que me quedaban. Mi amor de aquella necesidad había suprimido el pasado y toda atadura con el presente" (Onetti, 1975: 64). En segundo lugar, el fracaso del proyecto de casamiento metaforiza la imposibilidad de una salvación colectiva para el país y consolida la propensión típicamente "oriental" hacia una rememoración nostálgica del pasado. En particular, el uso en el relato de los tiempos verbales al pasado remite a uno de los textos esenciales de la narrativa de la decadencia urguaya: nos referimos a la novela Con las primeras luces (1966), en la que Carlos Martínez Moreno ofrece al lector un profético diagnóstico de un estado y una sociedad en vías de descomposición. En la novela, el protagonista, Eugenio, hijo de una familia patricia montevideana en decadencia, resulta mortalmente herido en el intento de superar-después de una noche de fiesta- las verjas del muro que rodea su misma casa: en su largo y agónico monólogo nocturno el uso del imperfecto subraya la añoranza del espacio-tiempo de lo posible: "Yo antes podía, a los diez, a los quince, a los veinte [...] Yo antes podía, claro que sí. También podía contra el dolor y contra las copas, todo con otra fe" (Martínez Moreno, 1966: 7). La desaparición de la fe individual se extiende hasta convertirse en una desesperanza colectiva, consolidando la lectura interpretativa que ve en el acercamiento inevitable de la muerte del protagonista la metáfora del derrumbe de un sistema ${ }^{9}$.

En el cuento onettiano, no sólo las posibilidades de comunicación entre seres humanos resultan imposibles, sino que de esta imposibilidad y de la desintegración de todo vínculo humano los personajes novelescos son conscientes; cuando el protagonistanarrador del relato se entrega a una aceptación pasiva del veto puesto por Bob al casamiento con Inés, en una actitud de anulación de toda resistencia a la prohibición, hace su aparición en la trama la conciencia de la inutilidad de la lucha y la lúcida percepción de que la caída es inevitable. En relación con esta dinámica de deterioro, Verani hace hincapié en la enajenación debida a la conciencia del desencuentro del ser humano con su misma vida: "Es indudable que los personajes de Onetti viven conscientes de la caída, origen y causa de la futilidad de todas sus acciones, de un estado de abandono que abarca diversos niveles de la realidad textual (física, espiritual, ética, social). Cambian las situaciones, cambian los personajes, pero en todo caso el esquema novelístico queda inalterado: la desintegración de todo vínculo" (Verani, 2009: 27). 


\section{En el inhóspito universo de la adultez: la añoranza del país de la juventud}

18 Puesto que el tiempo individual sobre el que se construye la tensión de la historia tiende a abolir la representación lineal del tiempo-evidenciando una descronologización que profundiza la percepción individual del transcurrir de los años- la segunda parte del cuento se desarrolla en el primer plano narrativo. Así, el relato del desenlace empieza en el que definimos como el "tiempo de la narración"; han pasado diez años, el contexto espacial es el mismo, pero la temporalidad lineal aparece deformada: "Ahora hace cerca de un año que veo a Bob casi diariamente, en el mismo café, rodeado de la misma gente. Cuando nos presentaron -hoy se llama Robertocomprendí que el pasado no tiene tiempo y el ayer se junta allí con la fecha de diez años atrás" (Onetti, 1975: 66). La fugacidad de la vida y el motivo de la imposible perduración de la juventud emergen para poner de relieve dos aspectos: primero, declamar la distancia existente entre la realidad de la caducidad humana y la eterna juventud a la que el Bob de entonces se creía destinado. La existencia no vendría a ser otra cosa que una serie de fragmentos temporales desarrollados en secuencia, a veces comprimiéndose, otras extendiéndose, consolidando "una noción filosófica de la existencia como suma de brevedades. Para Onetti, la sensación siempre presente de que la vida es muerte incesante es la causa del drama ontológico que viven sus personajes" (Verani, 2009: 74). En segundo lugar, la insistencia en la fugacidad de los años juveniles metaforiza la trayectoria (el breve vuelo pindárico y el declive) de la pequeña República, cuando ya el tiempo de la fiesta-que tan cercano parece todavía-- se ha desvanecido definitivamente.

Pronunciar el número treinta o cuarenta, para el Bob esperanzado de los años juveniles, no es otra cosa que expresar palabras vacías de significado: esos números parecían al adolescente de entonces meras entidades abstractas, en su enormidad inconcebible que se extendía en un tiempo futuro y muy lejano todavía (vuelven, aquí, las referencias a los años despreocupados de la bonanza económica y del auge cultural). Asimismo, los diez años que transcurren entre el primer encuentro y el desenlace de la historia, aun si no representan un intervalo temporal muy extenso, resultan suficientes para permitir el tránsito de la juventud a la adultez: franquear el límite de los treinta años, esa edad inconmensurablemente abstracta y remota para el Bob joven, significa acceder al mundo de la ausencia de ilusiones, donde no hay "nada más que costumbres y repeticiones, nombres marchitos" (Onetti, 1975: 65).

Si el transcurrir de los diez años ha convertido la juventud de Bob en una ausencia perdida para siempre, en cambio el relator ha guardado todo el odio que ha ido acumulando hacia el destructor de sus esperanzas. Este proceso de elaboración interna consolida la pertenecia del relato a una sección creativa de la producción onettiana caracterizada por una misma índole: la que presenta el paso del tiempo no ya -y no sólo- como causa de malestar cósmico y supraindividual, o como desconcertante gravamen ante el desvalido destino del hombre condenado a la vejez, sino como instrumento de venganza. Formarían parte de esta misma categoría de "Bienvenido Bob" los relatos "Un sueño realizado" y "Nueve de julio", así como lo subraya Jorge Ruffinelli: "La extraña mujer de 'Un sueño realizado' intenta cumplir sobre un escenario el sueño que la llevará a la infancia y (secretamente) a la muerte; el narrador de 'Bienvenido Bob" y el de "Nueve de julio" saben replicar a la soberbia de la juventud, 
el primero tan sólo esperando que pasen los años y el adolescente envejezca, desaparezca; el segundo al tocar el nervio más sensible de un muchacho, consciente de que así lo destruirá" (Ruffinelli, 1975: 7).

21 Los diez años transcurridos han provocado cambios tanto en la cara de Bob como en la imagen de la nación: si es dificil reconocer en ese rostro de hombre maduro y triste los rasgos del joven arquitecto esperanzado, resulta también arduo comparar el Uruguay de la década del veinte (hasta el Golpe de 1933) con el país que observa y describe Onetti. El nombre de juventud de Bob ha desaparecido y con él su cara juvenil, parecida a la de su hermana Inés: "Algún gastado rastro de Inés había aún en su cara, y un movimiento de la boca de Bob alcanzó para que yo volviera a ver el alargado cuerpo de la muchacha [...]. Pero era trabajoso escarbar en la cara, las palabras y los gestos de Roberto para encontrar a Bob y poder odiarlo" (Onetti, 1975: 66-67). De nuevo, el concepto de tiempo interior emerge en la narración: los diez años no han pasado -y pesado- de la misma manera sobre los dos personajes, puesto que el desarrollo lineal, cronológico y cuantitativo del tiempo ha dejado al narrador en la misma condición en la que se encontraba antes (es decir, un hombre hecho y deshecho), mientras que ha convertido -en ese mismo intervalo de tiempo aparentemente homogéneo- a Bob en un hombre deshecho de nombre Roberto. Resalta aquí la contraposición señalada por Fernando Aínsa entre el "tiempo del yo psicológico y su íntima duración [y] la proyección exterior, homogénea, cronológica, cuantitativa y mensurable de un tiempo simultáneo a otros tiempos exteriores" (Aínsa, 2006: 134).

En este nuevo tiempo marchito de la adultez, el narrador golpea al antiguo enemigo prometiéndole una amistad que durará para siempre (evidente la ironía en la frase: "una amistad que espero no terminará ya nunca"): el odio se mantendrá encerrado, cálido y nuevo, en el alma del narrador, mientras él pueda seguir viendo y escuchando a Roberto, simulacro envejecido del desafiante Bob de un tiempo. La engañosa amistad es, en realidad, una venganza urdida con paciencia: gracias, o por culpa del tiempo que pasa, Roberto ya no es más Bob, ya no es dueño de su futuro ni del mundo: "Hablo con él, sonrío, fumo, tomo café. Todo el tiempo pensando en Bob, en su pureza, su fe, en la audacia de sus pasados sueños. Pensando en el Bob que amaba la música, en el Bob que planeaba ennoblecer la vida de los hombres construyendo una ciudad de enceguecedora belleza [...] el Bob que proclamaba la lucha de jóvenes contra viejos, el Bob dueño del futuro y del mundo" (Onetti, 1975: 67). Bob ha fracasado no sólo porque está viviendo los mismos desengaños existenciales y las mismas desilusiones que le reprochaba a su despreciado enemigo adulto diez años antes, sino también por no haber sido capaz de convertirse en un "hombre extraordinario". Roberto no es otra cosa que un Bob fracasado: no ha realizado ninguno de sus deslumbrantes proyectos de los años de la facultad y está convirtiéndose -él también- en un hombre decadente que ha comenzado ya su inmersión en el tenebroso y maloliente mundo de los adultos. Asimismo, de los sueños y esperanzas del Uruguay de comienzos del siglo XX no quedan sino escombros y el país "que había vivido hasta ese momento en la feliz inconciencia de un generoso, aunque desigual, estado paternalista y que se vanagloriaba de estar culturalmente al día" (Aínsa, 2008: 556) vive una agonía lenta que consagra el derrumbe y la imposibilidad de regresar al origen del desgaste.

23 El proceso de elaboración de los acontecimientos vividos y de las consiguientes estrategias desarrolladas por el relator ocurre en él según un movimiento de doble sentido: una primera dirección va del pasado hacia el futuro (es decir, del momento de 
las humillaciones recibidas por parte del Bob joven hacia la etapa del reencuentro y de la venganza), y una segunda se mueve del futuro hacia el pasado. En este caso, en el plano de la narración lineal, el movimiento à rebours nace de las promesas del relator a Roberto de una amistad que duraría para siempre, en venganza por el recuerdo todavía vivo de los antiguos desprecios que el joven le manifestaba; en el plano metafórico, el viaje hacia el pasado surge de la comparación del presente con el tiempo breve de la presunta y perdida prosperidad colectiva. En este doble movimiento parecen reflejarse con una cierta evidencia las teorías que Paul Ricouer construye alrededor de las dinámicas de interrelación entre la memoria (tanto colectiva como personal) y el paso del tiempo; emblemático de esta asociación conceptual es el fragmento siguiente de La memoria, la historia, el olvido: "a la memoria se vincula el sentido de la orientación en el paso del tiempo; orientación de doble sentido, del pasado hacia el futuro, por impulso hacia atrás, en cierto modo, según la flecha del tiempo del cambio, y también del futuro hacia el pasado, según el movimiento inverso de tránsito de la espera hacia el recuerdo, a través del presente vivo" (Ricoeur, 2010: 129).

Finalmente, como última reflexión para concluir nuestro análisis, cabría señalar brevemente la vehemencia lexical que Onetti derrama en el relato: la adopción de adjetivos ásperos y agresivos parece consolidarse como instrumento del que el autor se sirve para articular una denuncia social desde la ficción. El uso que hace el autor de términos como "cadáveres pavorosos", “antiguas ambiciones", "formas repulsivas", “descomposición" o "proyectos sin convicción" resultan paradigmáticos de un fracaso existencial que se traduce en la ineluctabilidad del declive humano de Roberto, pero estas dinámicas de hundimiento "en la sucia vida de los hombres" no se limitan a afectar al protagonista del relato, sino que se extienden al contexto social y económicocultural de Uruguay, abarcando en su crítica todo el sistema social nacional y lanzando una señal de alarma alegórica cuyo eco fue captado -en la misma época y en los años siguientes- por varios destacados miembros de la ya mencionada Generación del ‘ 45 .

\section{BIBLIOGRAFÍA}

AÍNSA, Fernando (1970). Las trampas de Onetti. Montevideo: Alfa.

AÍNSA, Fernando (2006): Del topos al logos. Propuestas de geopoética. Madrid: Iberoamericana.

AÍNSA, Fernando (2008). Espacios de la memoria. Lugares y paisajes de la cultura uruguaya.

Montevideo, Trilce.

MARTÍNEZ MORENO, Carlos (1966). Con las primeras luces. Barcelona, Seix Barral.

NAVASCUÉS De, Javier (2007). Manual de literatura hispanoamericana VI. La época contemporánea: prosa. Pamplona: CÉNLIT.

ONETTI, Juan Carlos (1975). Cuentos completos. Buenos Aires: Círculo de Lectores S.A.C.I.

ONETTI, Juan Carlos (1989). Novelas y relatos. Caracas: Biblioteca Ayacucho.

REYES, Alfonso (1960). No hay tal lugar. Tomo XI de obras completas. México: FCE. 
RICOEUR, Paul (2010). La memoria, la historia, el olvido. Madrid: Editorial Trotta.

RUFFINELLI, Jorge (1975). Introducción a Cuentos completos. Buenos Aires: Círculo de Lectores S.A.C.I. (pp. 5-13).

VERANI, Hugo (2009). Onetti: el ritual de la impostura. Montevideo: Trilce. II. La amistad sin fin en el nuevo espacio de la adultez.

\section{NOTAS}

1. De entre los incontables textos críticos dedicados al apogeo y declive del Uruguay, señalamos el ensayo de Carlos Maggi El Uruguay y su gente. Montevideo, Alfa, 1965; el estudio Los marginados uruguayos. Teoría y realidad. Montevideo, Banda Oriental, 1986 (autores: Astori, Danilo; Castagnola, José Luis, Ferrando; Jorge; Marinoni, Mirtha; Martorelli, Horacio); Historia del Uruguay en el siglo XX. 1890-2005. Montevideo, Banda Oriental, 2007 (autores: Frega, Ana / Rodríguez Aycaguer, Ana María / Ruiz, Esther / Porrini, Rodolfo / Islas, Ariadna / Bonfanti, Daniele / Broquetas, Magdalena / Cuadro, Ines); y el texto de Fernando Aínsa: Espacios de la memoria. Lugares y paisajes de la cultura uruguaya. Montevideo, Trilce, 2008.

2. José Pablo Torcuato Batlle Ordóñez (Montevideo, 21 de mayo de 1856 - 20 de octubre de 1929), fue político y periodista y fue nombrado Presidente de la República en dos ocasiones: el primer mandato se remonta al período 1903 - 1907, el segundo al cuadrienio 1911 - 1915.

3. El personaje de Larsen actúa como hilo conductor de la saga sanmariana: en Juntacadáveres gestiona un burdel (recoge a mujeres perdidas y las hace trabajar en el prostíbulo). Si en un principio el negocio parece prosperar (no hay que olvidar que Larsen llega a Santa María como un ser fracasado que procede de anteriores frustraciones), los acontecimientos demuestran la inutilidad de todo esfuerzo humano: los habitantes de la ciudad obligan a cerrar el burdel y se le expulsa del espacio urbano. La inmediata moraleja que se desprende remite a la doble condena del pecador, que vuelve a fracasar y es -además- empujado hacia el "afuera", en exilio. Cuando, cinco años después, Larsen vuelve a Santa María con un proyecto aun más alocado (revitalizar un astillero que desde hace tiempo está en ruinas) el lector percibe que la única esperanza que todavía persiste en el alma del antihéroe onettiano es la de casarse con la hija semidemente del rico y decaído dueño del astillero (como revancha contra los habitantes de la ciudad que lo habían expulsado). El fracaso de este segundo intento (el astillero es irrecuperable, todos los seres involucrados en la empresa alocada son individuos fracasados, que se pierden) consolida el destino de insalvable hundimiento de los personajes onettianos.

4. La murga uruguaya suele ser interpretada por un coro compuesto un número fijo de coreutas, (entre 13 y 17 miembros), que no sólo entona canciones sino que realiza cuadros musicales con personajes definidos y siguiendo una línea argumental. Las temáticas principales se concentran en los acontecimientos más relevantes del año, con crítica política y social. El coro es normalmente acompañado por una 'batería de murga', integrada por instrumentos como el bombo, los platillos y el redoblante, que toca el ritmo conocido como 'marcha camión'.

5. Utilizando una terminología frecuente en los estudios que Paul Ricoeur dedica al tema de la memoria y de los efectos del tiempo sobre ella, podría afirmarse que la postura del relator acerca de la percepción del paso del tiempo revela "la emergencia de una problemática de la subjetividad claramente egológica” (Ricouer, 2010: 126).

6. Cuando irrumpe en escena el boom latinoamericano, Onetti (1909-1994) es ya un autor maduro. La consagración de la gran literatura del subcontinente permite una recuperación de su obra (en la que no hay nada del tropicalismo humorístico de Márquez), y el escritor montevideano se convierte en un referente para la generación siguiente. Cuando el Uruguay se hundió en la crisis político-económica que estalló definitivamente en la década del setenta, el trauma fue coletivo 
pues marcó el fin de la ilusión de seguir siendo la feliz excepción del continente. El mundo cultural uruguayo se expresó de manera crítica hacia el sistema: el objetivo polémico de la generación de Onetti, en particular, fue la cerrazón mental de la gente, en un Estado que se había consolidado desde comienzos del siglo XX gracias a un avanzado sistema de bienestar. La descripción de grises empleados sin ilusiones ni esperanzas, de sus rutinas diarias, de deberes mecánicos sin explicación, inscriben a los personajes de Onetti en un espacio prototípico (en compañía de los de Rodolfo Walsh, Osvaldo Soriano, Mario Benedetti) de una tendencia dentro de la literatura rioplatense: se trata de personjaes fracasados, seres sin perspectivas vitales cuyas experiencias reflejan la soledad del hombre contemporáneo. Asimismo, cabe también observar cómo en la producción onettiana resulta muy evidente tanto la influencia de sus reconocidos maestros (Louis-Ferdinand Celine y William Faulkner), como del existencialismo francés: en este segundo caso, los escritores de la década del cincuenta adaptan las formas originales del existencialismo para releer la realidad latinoamericana, apuntando al empeño político del intelectual, llamado a actuar en primera persona.

7. La elección del nombre Inés por parte de Onetti parece evidenciar una suerte de 'determinismo onomástico': muchas 'Ineses' de la literatura no sólo intentan salvar a los Don Juanes, sino que funcionan como la posibilidad de redención de un personaje masculino (el nombre aparece en Don Juan Tenorio de Zorrilla, en El burlador de Sevilla de Tirso de Molina, y-dentro del marco literario rioplatense- en Barranca Abajo de FlorenciaoSánchez, en el Don Juan de Leopoldo Marechal). En "Bienvenido Bob", coherentemente con la visión desesperanzada de la existencia que expresa Onetti, Inés representa sólo un 'instrumento de salvación potencial e hipotética' que no logra la redención del protagonista masculino.

8. Se vislumbra en el fragmento que se cita una suerte de perverso regodeo en la humillación: se trata de una actitud que remite al cultivo de la frustración debida al fracaso anunciando, como señala Navascués aplicando sus reflexiones al personaje de Larsen: “Ésta es quizás la quintaesencia de los héroes onettianos: su pesimista lucidez y su voluntad de fracaso contra toda esperanza. La Conciencia de la propia derrota, de su capacidad de asquearse de sí mismo, acompaña el derrotero de Larsen a lo largo de toda la acción" (NAVASCUÉS, 2007: 149).

9. Al analizar la novela de Martínez Moreno, Aínsa afirma que, en la agonía de la entonces pudiente familia, se refleja la historia de un país, observando cómo "una familia unida, rica, segura de ella misma se deshacía entre los coletazos de una crisis en la que un patrimonio se desmantelaba sin pena ni gloria. Los grandes mitos del país se degradaban" (Aínsa, 2008: 133).

\section{RESÚMENES}

El presente estudio propone una relectura del relato onettiano "Bienvenido Bob", concentrando la atención en la conexión alegórica que existe entre la inexorabilidad del desgaste producido en el ser humano por el transcurso de los años y el derrumbe progresivo del sistema socioeconómico y político del Uruguay. El abordaje propuesto apunta a subrayar la relevancia de dos motivos dominantes del relato: a la subjetividad en los procesos perceptivos del paso del tiempo -y, por ende, a la distinción entre tiempo vivido y tiempo físico- se añade una serie de reflexiones acerca de la arquitectura temporal del cuento, que insiste en el motivos del declive subjetivo como metaforización de la decadencia que tuvo que enfrentar el país y de la paulatina descomposición de los cimientos en los que se fundaba el sistema batllista. El fin de fiesta al que se hace 
referencia en el título remite, así, al comienzo de la pauperización nacional, que implanta sus raíces ya a partir de la década del treinta.

L'étude présentée propose une relecture du conte 'Bienvenue Bob' de Juan Carlos Onetti, en concentrant l'attention sur la connexion allégorique existante entre l'inexorabilité de l'usure produite chez l'être humain par le cours des années et l'écroulement progressif du système socioéconomique et politique de l'Uruguay. L'approche souligne l'importance de deux motifs dominants du conte: D'une part, l'étude de la subjectivité dans les processus perceptifs du passage du temps - c'est à dire, la distinction entre le temps vécu et le temps physique - D'autre part, une série de réflexions à propos de l'architecture temporelle du conte, insistant sur les motifs du déclin subjectif comme métaphore de la décadence qui a frappé le pays et de la lente décomposition des fondations sur lesquelles s'appuyait le système crée pour José Batlle. La fin de la fête à laquelle le titre fait référence amorce le commencement de l'appauvrissement national, qui s'observe déjà à partir de la décennie trente.

\section{ÍNDICE}

Palabras claves: Carlos Onetti (Juan), literatura uruguaya, subjetividad perceptiva, tiempo individual-tiempo colectivo, declive socioeconómico, fin de fiesta

Mots-clés: Carlos Onetti (Juan), littérature uruguayenne, subjectivité perceptive, temps individuel-temps collectif, déclin socio-économique, fin de fête

\section{AUTOR}

\section{GIUSEPPE GATTI}

Università La Sapienza - Roma / UTIU - Università Telematica Internazionale UniNettuno Roma. "Doctor Europeus" cum laude en Literatura española e hispanoamericana por la Universidad de Salamanca, España. Su tesis doctoral "La apropiación subjetiva del espacio urbano. Montevideo y su proyección en la literatura de Hugo Burel" ha sido galardonada con el Premio Extraordinario de Doctorado por la Universidad de Salamanca, diciembre de 2011. Actualmente se desempeña en la Universidad La Sapienza, Roma; Facoltà di Filosofia, Lettere, Scienze Umanistiche e Studi Orientali, como adscripto a la Cátedra de Lengua y literaturas hispanoamericanas en calidad de "Cultor de la materia", y en la UTIU - Università Telematica Internazionale UniNettuno, Roma; Facoltà di Scienza della Comunicazione, como asistente/tutor de la Cátedra de Lengua española. giuseppe_gatti[at]hotmail.com 